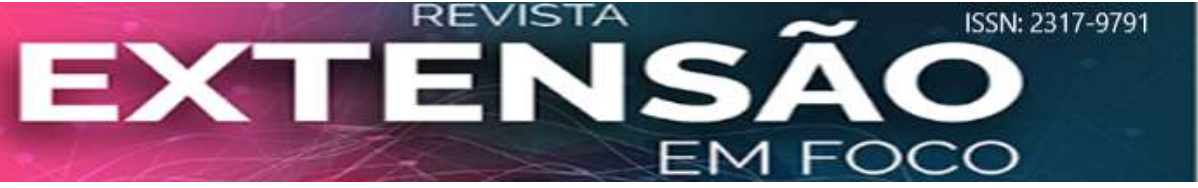

\title{
INTERAÇÕES E BRINCADEIRAS COMO METODOLOGIA DE INCLUSÃO NA
}

\section{EDUCAÇÃO INFANTIL}

\author{
Circe Mara Marques \\ https://orcid.org/0000-0002-2137-4760 \\ Luciana Bicca ${ }^{2}$ \\ https://orcid.org/0000-0002-4558-4471 \\ Luiza Inês Kaim ${ }^{3}$ \\ https://orcid.org/0000-0002-7026-6061 \\ Marli Aparecida da Silva 4 \\ https://orcid.org/0000-0002-1443-5924 \\ Thaís de Oliveira ${ }^{5}$ \\ https://orcid.org/0000-0002-4062-0066 \\ Zenaide da Rocha Fragata Miranda ${ }^{6}$ \\ https://orcid.org/0000-0001-7383-3634
}

Recebido em: 30 nov. 2020

Aceito em: 15 dez. 2020

\begin{abstract}
RESUMO: Este artigo trata da inclusão na educação infantil. O objetivo foi conhecer os modos de interações entre crianças com e sem deficiência na escola de educação infantil. A pesquisa se constituiu em um estudo de caso e os dados foram produzidos a partir de observações em uma escola pública, localizada no oeste catarinense. Os participantes pertencem a uma turma de educação infantil, constituída por 22 crianças de 4 anos de idade, sendo uma delas com deficiência. Os resultados mostraram que as crianças protagonizam movimentos inclusivos em seus contextos de brincadeiras. Nesse sentido, entende-se a brincadeira como uma potente metodologia inclusiva na infância.
\end{abstract}

Palavras-chave: Educação Infantil. Inclusão. Brincar.

\section{INTERACTIONS AND CHILDREN'S PLAY AS A METHODOLOGY OF INCLUSION}

\section{IN EARLY CHILDHOOD EDUCATION}

\footnotetext{
1 Doutora em Educação (UFRGS). Professora no Programa de Pós-Graduação em Educação da Universidade Alto Vale do Rio do Peixe, em Caçador (SC), e no Programa de Pós-Graduação em Educação da Universidade Comunitária da Região de Chapecó, em Chapecó (SC). E-mail: circemaramarques@gmail.com

2 Mestranda do Programa de Mestrado Profissional em Educação Básica da Universidade Alto Vale do Rio do Peixe (Uniarp), em Caçador (SC). Professora no Centro Universitário UNIDEP e Intérprete de Libras na SEED PR. Psicóloga Clínica. E-mail: luciannabicca@gmail.com

3 Mestre em Educação pela Universidade Alto Vale do Rio do Peixe (Uniarp), em Caçador (SC). Professora de Libras do Instituto Federal Catarinense - Campus Videira. E-mail: luizatarefa@gmail.com ${ }^{4}$ Mestranda do Programa de Mestrado Profissional em Educação Básica da Universidade Alto Vale do Rio do Peixe (Uniarp), em Caçador (SC). E-mail: silvamarli33@yahoo.com.br

${ }^{5}$ Mestranda do Programa de Mestrado Profissional em Educação Básica da Universidade Alto Vale do Rio do Peixe (Uniarp), em Caçador (SC). E-mail: thaisbiancag@gmail.com

${ }^{6}$ Mestranda do Programa de Mestrado Profissional em Educação Básica da Universidade Alto Vale do Rio do Peixe, em Caçador (SC). Professora no curso de Educação física da UNIDEP e Tutora da disciplina de Libras do grupo Afya. E-mail: zenaidefragata@hotmail.com
} 
ABSTRACT: This article deals about children's social inclusion in early childhood education. The objective was to know the ways of interactions between children with and without disability at early childhood education school. The research was constituted in a case's study and the data were produced from observations in a public school, located in Santa Catarina west region. The participating children belong to a childhood education class, constituted by 22 children with 4 years old, one of them with a disability. The results showed that children lead inclusive movements in their play contexts. In this sense, we understand the children's play as a powerful inclusive methodology in childhood.

Keywords: Early Childhood Education. Inclusion. Play.

\section{INTRODUÇÃO}

A Educação como Direito de Todos é uma meta social, política e educacional que vem sendo perseguida pelos dirigentes da nação brasileira e pela população em geral. Considerando esse princípio constitucional, é dever do Estado garantir que a educação para todos se concretize. Contudo, no ambiente escolar, muitos são os desafios a serem enfrentados, abarcando a adaptação curricular, formação de professores, organização dos materiais, tempos e espaços escolares.

Este estudo apresenta o recorte de uma pesquisa maior que tratou da inclusão de crianças com deficiência na escola. O objetivo foi conhecer os modos de interações entre crianças com e sem deficiência na escola de educação infantil.

Embora todas as crianças sejam diferentes, algumas delas são mais por apresentarem algum tipo de deficiência, transtorno global de desenvolvimento ou superdotação. Ao chegarem na escola regular, essas crianças, na maioria das vezes, desconfiguram a rotina da instituição e da sala de aula. É comum que se escutem narrativas por parte de docentes acerca dos desafios e das dificuldades em lidar com tais sujeitos que viram pelo avesso o currículo uniforme e pré-programado da escola com o qual estamos tão familiarizados.

\section{INCLUSÃO E EDUCAÇÃO INFANTIL NO BRASIL}

A Constituição Federal de 1988 definiu a educação como um direito de todos, implementando a educação inclusiva. Em seu artigo 206, inciso I, estabeleceu a "igualdade de condições para o acesso e permanência na escola;" (BRASIL, 1988) como um dos princípios para o ensino e garantiu, como dever do Estado, a oferta do atendimento educacional especializado, preferencialmente na rede regular de ensino (BRASIL, 1988, art. 208).

Posteriormente, o Estatuto da Criança e do Adolescente (ECA), Lei n. ${ }^{\circ}$ 
8.069/90, reafirma o direito de todas as crianças à educação, determinando, no artigo 55, que "Os pais ou responsáveis têm a obrigação de matricular seus filhos ou pupilos na rede regular de ensino." (BRASIL, 1990). Outros documentos internacionais como a Declaração Mundial de Educação para Todos (1990) e a Declaração de Salamanca (1994) também influenciaram a formulação das políticas públicas da educação inclusiva.

A Lei de Diretrizes e Bases da Educação Nacional (LDBEN), artigo 58, parágrafo $3^{\circ}$, estabelece que a educação especial, modalidade de educação escolar oferecida para educandos com necessidades especiais, incluindo os deficientes, deve ser oferecida desde a Educação Infantil (BRASIL, 1996). Em seu artigo 59, preconiza que os sistemas de ensino devem assegurar aos alunos currículo, métodos, recursos e organização específicos para atender às suas necessidades (BRASIL, 1996).

O Plano Nacional de Educação (PNE), Lei n. ${ }^{0}$ 10.172/2001, destaca que "[...] o grande avanço que a década da educação deveria produzir será a construção de uma escola inclusiva, que garanta o atendimento à diversidade humana." (BRASIL, 2001). Ao estabelecer objetivos e metas para que os sistemas de ensino favoreçam o atendimento às necessidades educacionais especiais dos alunos, aponta deficits referentes à oferta de matrículas para alunos com deficiência nas classes comuns do ensino regular, à formação docente, à acessibilidade física e ao atendimento educacional especializado. Mais tarde, o novo Plano Nacional de Educação (PNE), Lei . $^{\circ}$ 13.005/2014, assegura o sistema educacional inclusivo em todos os níveis, etapas e modalidades (BRASIL, 2014).

O documento O Acesso de Alunos com Deficiência às Escolas e Classes Comuns da Rede Regular, publicado em 2004 pelo Ministério Público Federal (MPF), objetivou tanto a disseminação dos conceitos e diretrizes mundiais para a inclusão como a reafirmação do direito e aos benefícios da escolarização de crianças com e sem deficiência nas turmas comuns do ensino regular.

No contexto específico da educação infantil, as Diretrizes Curriculares Nacionais para a Educação Infantil (DCNEI) (Resolução CNE/CEB n. ${ }^{\circ}$ 5/2009 e Parecer CNE/CEB n. ${ }^{\circ}$ 20/2009) orientam que

Art. $4^{\circ}$ As propostas pedagógicas da Educação Infantil deverão considerar que a criança, centro do planejamento curricular, é sujeito histórico e de direitos que, nas interações, relações e práticas cotidianas que vivencia, constrói sua identidade pessoal e coletiva, brinca, imagina, fantasia, deseja, aprende, observa, experimenta, narra, questiona e constrói sentidos sobre a natureza e a sociedade, produzindo cultura. (BRASIL, 2009, p. 1). 
Nesse sentido, as DCNEI (2009), em seu artigo $9^{\circ}$, destacam que as interações e as brincadeiras devem ser os eixos norteadores das propostas. Com relação ao atendimento das crianças com deficiência, esse documento aponta em seu artigo $8^{\circ}$, inciso VII, que as propostas pedagógicas devem promover condições para o trabalho coletivo e para organização de materiais, espaços e tempos que assegurem "a acessibilidade de espaços, materiais, objetos, brinquedos e instruções para as crianças com deficiência, transtornos globais de desenvolvimento e altas habilidades/superdotação;" (BRASIL, 2009, p. 3).

Também a Base Nacional Comum Curricular (BNCC) destaca seis Diretos de Aprendizagem: conviver, brincar, participar, explorar, expressar e conhecer-se (BRASIL, 2017). Esses direitos também constituem eixos a serem observados tanto no planejamento docente como na produção de registros sobre as trajetórias e o desenvolvimento das crianças em escolas de educação infantil.

Hoje, apesar do amparo legal que garante o direito de todos à educação, as crianças ainda vivem o risco de serem incluídas em espaços escolares sem infraestrutura básica de acessibilidade e ou carentes de profissionais qualificados para interagir e brincar com elas.

Entendemos que cada criança na educação infantil tem o direito a tempos e espaços apropriados para aprender, ser cuidada e educada para ser o melhor daquilo que é. Nesse sentido, interessa-nos conhecer os modos como os processos de inclusão na educação infantil integram as ações de cuidar, ensinar e educar.

\section{METODOLOGIA}

Trata-se de uma pesquisa qualitativa abarcando estudo de caso e pesquisa com crianças. Os dados foram produzidos em uma escola pública, localizada em um município do oeste catarinense. Participaram da pesquisa uma turma de educação infantil de 4 anos de idade. A turma estava constituída por 22 crianças, sendo que uma delas apresentava dificuldade na marcha e na fala. A menina frequentava a Associação de Pais e Amigos dos Excepcionais (APAE) em outro município da região, e a família, até o momento da realização da pesquisa, não havia apresentado o laudo médico.

Para a produção dos dados foram realizadas observações nos diferentes momentos da rotina: acolhida, alimentação, brincadeiras livres no pátio, atividades de 
aprendizagem em sala de aula, higiene.

Os dados foram registrados em um caderno de campo, sendo que também foi feito uso de imagens fotográficas e de vídeo. $O$ estudo foi aprovado pelo comitê de ética. A identidade da criança foi preservada, adotando-se o nome fictício de Ana para identificar a participante com deficiência.

\section{DO COLO DA MÃE A MÃOS DADAS COM OS PARES: OS RESULTADOS DA}

\section{PESQUISA}

Ana tem 4 anos e está frequentando uma Escola Municipal de Educação Infantil (EMEI) há dois meses. A família mudou-se para o município do oeste catarinense e informou que a menina não havia frequentado a escola, somente a APAE do município de origem. Moram no mesmo bairro da escola, contudo, segundo relato da professora: "É um problema trabalhar com Ana, porque falta bastante e quando vem chora até que a gente chame a mãe. Acho que ela não vai se adaptar na escola. A mãe está tentando uma vaga na APAE." (informação verbal)7. A professora também informou que a família é relapsa e que até agora não trouxe o laudo médico: "[...] já cansamos de pedir pra mãe e ela diz que vai trazer e nunca traz. Parece que perdeu na mudança e também não sabe explicar direito o que a Ana tem. Sem saber o que ela tem e sem laudo é difícil saber o que fazer." (informação verbal) ${ }^{8}$.

Soncini (2016) destaca que antes de conhecer o diagnóstico é preciso que os professores busquem conhecer a própria criança. Também Zortéa (2011, p. 51) conclui que "[...] assim como não podemos dizer aos médicos sobre como tratar seus pacientes, do mesmo modo não podemos pedir a eles ou outros especialistas que nos digam sobre como daremos conta na escola das aprendizagens das nossas crianças $[\ldots] "$.

A Secretaria Municipal de Educação disponibiliza um profissional de apoio (PA) para dar suporte à professora no atendimento de Ana. Essa profissional é estudante do terceiro semestre de Pedagogia e está contratada para estágio em escola.

Ao iniciarmos a coleta de dados, observamos que as crianças brincavam, corriam, gargalhavam no pátio da escola enquanto aguardavam o sinal para entrarem para suas salas. Algumas mães conversavam enquanto acompanhavam com os olhos

\footnotetext{
${ }^{7}$ Fala da professora registrada durante as observações. Dados coletados na EMEl.

${ }^{8}$ Fala da professora registrada durante as observações. Dados coletados na EMEI.
} 
os movimentos de seus filhos até que as professoras chegassem. Também ali, observamos a cena de Ana no colo da mãe, ambas sem esboçar qualquer sorriso, deixando transparecer que se sentiam desconfortáveis no portão da escola. Aliás, a própria mãe já havia afirmado sua preferência em manter a filha apenas na APAE. Esse desconforto também emergiu no relato da professora quando informou sobre as muitas faltas de Ana e a ausência da família, sobre os choros para permanecer na escola e a pouca interação com os pares.

No momento de entrar na sala, Ana entrelaçava os braços no pescoço da mãe e escondia o próprio rosto, sem olhar para a professora e colegas. Entrelaçava as pernas na cintura da mãe quando essa tentava colocá-la no chão e chorava baixinho. A professora e a profissional de apoio a convidavam para entrar e ofereciam brinquedos. Em seguida, a professora se afastava para atender às demais crianças que chegavam. A PA seguia tentando separar a criança da mãe. Essa cena se repetia quase que diariamente. Em dado dia, depois que a mãe de Ana foi embora, a professora, visivelmente insatisfeita com a situação, comentou com a pesquisadora:

É sempre assim, a mãe não colabora e faz todas as vontades dela. Depois que vai embora, ela para de fazer manha. Antes ela chorava muito. Agora já é bem mais fácil - só que a Ana não fala, não interage, não brinca e nem faz nada sozinha. É difícil lidar com ela. (Informação verbal) ${ }^{9}$.

Durante os momentos de brincadeira livre dentro da sala, no decorrer do primeiro mês de observação, foram mínimas as interações de Ana com os pares. Ela era mais uma observadora, daquilo que acontecia no grupo, do que um sujeito participante do grupo. As crianças sentavam em mesas coletivas, em grupos de cinco. A profissional de apoio, que acompanhava Ana durante as aulas, avisou que devido à dificuldade de mobilidade motora, ela tinha uma cadeira diferenciada na sala. Explicou que a cadeira de madeira mais pesada e com o assento maior era mais segura para que ela pudesse sentar e levantar sem cair ou derrubar a cadeira. A PA alcançava jogos de encaixe para Ana e mostrava como encaixar as peças. A interação se dava mais entre elas de modo que Ana não abordava seus pares e não era abordada por eles. Durante as interações com a PA, percebíamos que, embora não se expressasse verbalmente, ela compreendia e, algumas vezes, respondia com gestos simples, balançando a cabeça em sinal afirmativo ou negativo.

Para se deslocarem de um espaço para outro, as crianças costumavam formar

${ }^{9}$ Fala da professora registrada durante as observações. Dados coletados na EMEI. 
fila, enquanto que Ana caminhava de mãos dadas com a PA. Em dado momento, Ana espontaneamente colocou-se na fila com o grupo. Ela caminha com desequilíbrio e precisa de apoio. Durante o deslocamento, Ana apoiava-se segurando fortemente no casaco rosa da colega da frente. Essa menina sentava-se no mesmo grupo de Ana e algumas vezes interagiu com ela e a PA. Enquanto a fila se deslocava, em dados momentos a menina do casaco rosa parava, olhava para trás e ajeitava seu casaco, que estava sendo puxado por Ana, parecendo compreender que aquele apoio era importante para a colega. Nos demais dias, Ana novamente se colocou na fila, sempre atrás da mesma colega, apoiando-se firmemente no casaco dela. Não era acaso existia uma cumplicidade entre Ana e a menina do casaco rosa. Em certa ocasião, a PA comentou com a pesquisadora: "Parece que Ana está gostando de imitar ela [a menina do casaco rosa]." (informação verbal)10.

O balanço era o lugar onde Ana permanecia durante os recreios no pátio, sendo embalada pela PA. Do alto do balanço, ela silenciosamente acompanhava as diferentes brincadeiras, correria e risadas. Certo dia, enquanto era embalada, Ana ia e voltava com a cabeça virada observando um grupo de colegas que brincava de fazer comidinhas na areia, entre elas, a menina do casaco rosa. A PA, então, foi até o grupo de quatro crianças e fez a seguinte mediação:

- O que vocês estão brincando? (PA)

- Tamos fazendo aniversário. Vai ter bolo e um monte de docinhos. Até pastel. (Menina do casaco rosa)

- Acho que a Ana gostaria de brincar de aniversário. (PA)

- Mas ela só fica no balanço. Todos os dias! (Criança1)

- É, ela nunca sai de lá. (Crianças 3 e 4)

- $O$ que vocês acham de buscar ela? (PA)

(Informação verbal) ${ }^{11}$.

A criança 1 e a menina do casaco rosa não hesitaram. Saíram dali e foram até o balanço buscar Ana. Trouxeram-na de mãos dadas. Ana caiu sentada na areia e as colegas caíram junto, riram, levantaram, ajudaram Ana a levantar e a chegar no local onde preparavam as comidinhas. Elas alcançaram potinhos para brincar na areia, contaram sobre a brincadeira que estavam fazendo e ensinaram Ana a fazer bolinhos:

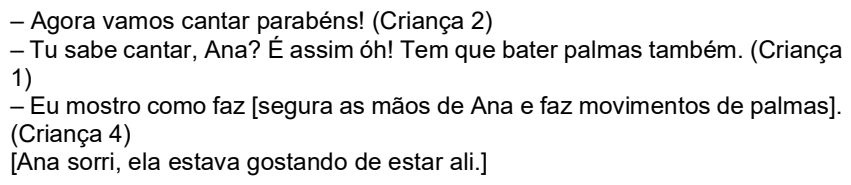

${ }^{10}$ Fala da professora de apoio registrada durante as observações. Dados coletados na EMEI.

${ }^{11}$ Diálogo entre a PA e as crianças registrado durante as observações. Dados coletados na EMEI. 
(Informação verbal) $)^{12}$.

Esse momento impulsionou uma série de outros momentos em que as crianças fizeram movimentos inclusivos durante as brincadeiras, entre eles a situação em que Ana falou. Dentro da sala, duas crianças (2 e 3) brincavam com telefone feito de latinhas. Essa brincadeira consiste em unir duas latinhas com um fio de barbante. Cada criança segura uma latinha, mantendo uma distância em que o fio possa ficar esticado. Uma das crianças segura o fone [latinha] no ouvido enquanto a outra fala na latinha para ser escutada pelo/a colega que tem o fone [latinha] no ouvido. Então, a menina do casaco rosa dirige-se à Ana e diz:

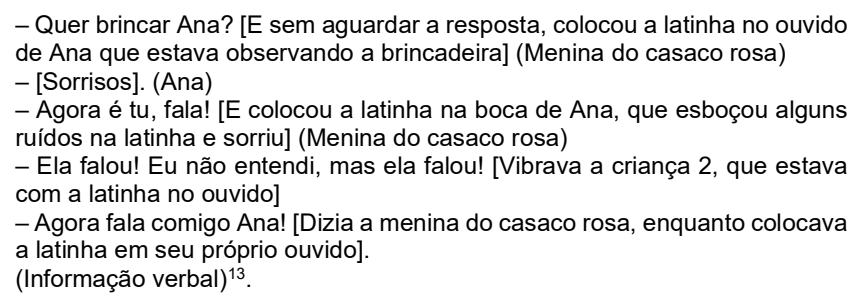

Cerca de dois meses depois do ingresso na escola regular, Ana se mostrava cada vez mais interessada em participar das brincadeiras na sala e no pátio. A menina do casaco rosa foi uma ponte para que Ana fosse incluída no grupo. Em outras situações, já foi possível identificar iniciativas dela no sentido de se aproximar de outros pares e de participar de certas brincadeiras. Do mesmo modo, também foi possível observar a potência dos movimentos das crianças sem deficiência no sentido de ensinar, cuidar e brincar com crianças com deficiência.

\section{CONSIDERAÇÕES FINAIS}

Para além da acolhida na escola, as crianças com deficiência têm direito a aprender, interagir e brincar. A mediação pedagógica por parte de professores e profissionais de apoio pode promover ou atravancar o processo inclusivo, dependendo dos caminhos escolhidos. Se o caminho for o disciplinamento da criança nos tempos e espaços da escola, bem como o treinamento para que ela consiga realizar as mesmas tarefas que os demais colegas, possivelmente, a criança com deficiência

\footnotetext{
12 Diálogo entre as crianças registrado durante as observações. Dados coletados na EMEI.

${ }^{13}$ Diálogo entre as crianças e Ana registrado durante as observações. Dados coletados na EMEI.
} 
ficará em desvantagem no grupo.

A brincadeira, por outro lado, é uma linguagem potente entre as crianças e reconhecida como direito de aprendizagem na BNCC. Destacamos aqui que não estamos tratando daquelas brincadeiras que são dirigidas pelos adultos, mas daquelas que emergem nas relações entre as crianças. Essas brincadeiras, como podemos ver neste estudo, constituem-se em metodologia de inclusão na infância, sendo que esse processo inclusivo é protagonizado pelas próprias crianças com e sem deficiência.

A observação sensível por parte do adulto pode iluminar possibilidades de aproximação entre as crianças com e sem deficiência como nos mostrou a PA quando percebeu a afinidade entre Ana e a menina do casaco rosa e atuou no sentido de oportunizar situação de interação e brincadeiras. Na sequência, as próprias crianças criaram e concretizaram movimentos inclusivos nos diferentes espaços e momentos da rotina escolar.

\section{REFERÊNCIAS}

BRASIL. Lei n. ${ }^{\circ}$ 8.069, de 13 de julho de 1990. Dispõe sobre o Estatuto da Criança e do Adolescente e dá outras providências. São Paulo: CBIA-SP, 1991.

BRASIL. Lei $\mathbf{n} .^{\circ}$ 9.394, de 20 de dezembro de 1996. Estabelece as Diretrizes e Bases da Educação Nacional. Brasília, DF: Ministério da Educação, 1996.

BRASIL. Lei n. ${ }^{\circ}$ 10.172, de 9 de janeiro de 2001. Aprova o Plano Nacional de Educação e dá outras providências. Brasília, DF, 2001.

BRASIL. Lei n. ${ }^{\circ}$ 13.005, de 25 de junho de 2014. Aprova o Plano Nacional de Educação - PNE e dá outras providências. Plano Nacional de Educação (PNE) 2014-2023. Brasília, DF, 2014.

BRASIL. Ministério da Educação. Base Nacional Comum Curricular: Educação Infantil e Ensino Fundamental. Brasília, DF: MEC/Secretaria de Educação Básica, 2017.

BRASIL. Resolução $\mathbf{n}^{\circ}$ 5, de 17 de dezembro de 2009. Fixa as Diretrizes Curriculares Nacionais para a Educação Infantil. Brasília, DF: Ministério da Educação, CNE/CEB, 2009.

MINISTÉRIO PÚBLICO FEDERAL - MPF. O Acesso de alunos com deficiência às escolas e classes comuns da rede regular. Brasília, DF: MPF, 2004.

SONSINI, Ivana. Comunidade inclusiva. In: EDWARDS, Carolyn; GADINI, Lella; FORMAN, George (org.). As cem linguagens da criança: e experiência de Reggio Emília em transformação. Porto Alegre: Penso, 2016. p. 187-208. 
ZORTÉA, Ana Maria. Inclusão na educação infantil: as crianças nos (des)encontros com seus pares. Porto Alegre: Redes Editora, 2011. 